\title{
Human multipotent mesenchymal stromal cells cytokine priming promotes RAB27B- regulated secretion of small extracellular vesicles with immunomodulatory cargo
}

Anastasia Cheng ${ }^{1}$, Dongsic Choi ${ }^{1}$, Maximilien Lora ${ }^{1}$, Dominique Shum-Tim² ${ }^{2}$ Janusz Rak ${ }^{1}$ and Inés Colmegna ${ }^{1,3^{*}}$ (D)

\begin{abstract}
Background: The paracrine effects of multipotent mesenchymal stromal cells (MSCs) are mediated by their secretome composed by soluble factors (i.e., cytokines, growth factors, hormones) and extracellular vesicles (EVs). EVs promote intercellular communication, and the EV cargoes [e.g., proteins, soluble factors, microRNAs (miRNAs), messenger RNA (mRNA), DNA] reflect the molecular and functional characteristics of their parental cells. MSCderived EVs (MSC-EVs) are currently evaluated as subcellular therapeutics. A key function of the MSC secretome is its ability to promote immune tolerance (i.e., immunopotency), a property that is enhanced by priming approaches (e.g., cytokines, hypoxia, chemicals) and inversely correlates with the age of the MSC donors. We evaluated mechanisms underlying MSC vesiculation and the effects of inflammation and aging on this process.

Methods: We evaluated the effects of interferon gamma (IFN- $\gamma$ ) and tumor necrosis factor alpha (TNF-a) on human adipose-derived MSC: (a) vesiculation (custom RT ${ }^{2}$ Profiler PCR Array), (b) EV profiles (Nanoparticle Tracking Analysis and Nanoparticle Flow Cytometry), (c) EV cargo (proteomic analysis and Western blot analysis), and (d) immunopotency (standard MSC:CD4 T cell proliferation inhibition assay). We confirmed the role of RAB27B on MSC vesiculation (RAB27B siRNA) and assessed its differential contribution to vesiculation in adult and pediatric MSCs (qPCR).
\end{abstract}

Results: Cytokine priming upregulated RAB27B in adipose-derived MSCs increasing their secretion of exosome-like small EVs (sEVs; $<200 \mathrm{~nm}$ ) containing two key mediators of immunopotency: A20 and TSG-6. These EVs inhibited T cell proliferation in a dose-dependent manner. RAB27B siRNA inhibited MSC vesiculation. Adipose-derived MSCs isolated from pediatric donors exhibited higher RAB27B expression and secreted more sEVs than adult MSCs.

Conclusions: Cytokine priming is a useful strategy to harvest anti-inflammatory MSC-sEVs for clinical applications. Of relevance, donor age should be considered in the selection of MSC-sEVs for clinical applications.

Keywords: Multipotent mesenchymal stromal cells, MSC, Extracellular vesicles, Exosomes, sEVs, RAB27B, TSG6, A20

\footnotetext{
*Correspondence: ines.colmegna@mcgill.ca

${ }^{1}$ Research Institute of the McGill University Health Centre, McGill University,

1001 Decarie Blvd, Office \# EM2-3238, Montreal, QC H4A 3J1, Canada

${ }^{3}$ Division of Rheumatology, Department of Medicine, McGill University,

Montreal, QC, Canada

Full list of author information is available at the end of the article
}

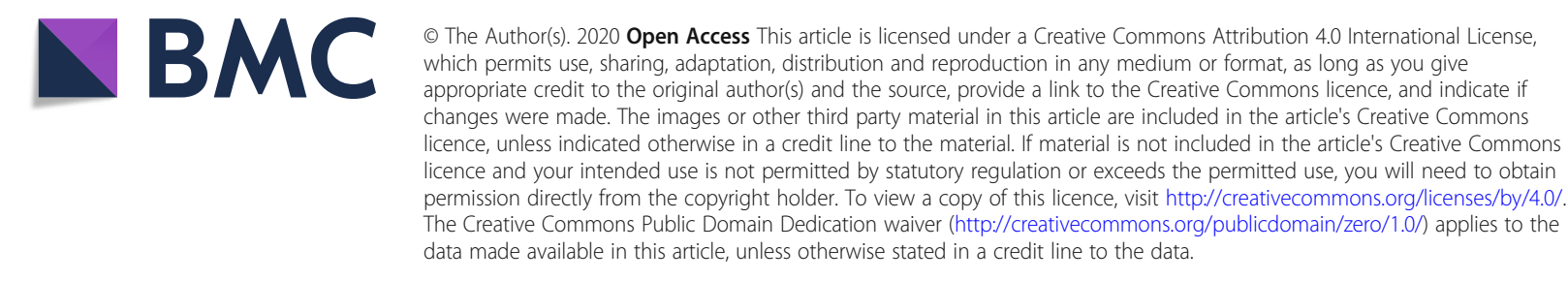




\section{Background}

Mesenchymal stromal cells (MSCs) are a heterogeneous group of multipotent progenitor cells that can be isolated from adult tissues [e.g., bone marrow (BM), adipose (AT)]. MSCs possess functional properties (e.g., high expansion capacity, low immunogenicity, antiinflammatory/pro-angiogenic, and anti-fibrotic effects) that motivate their use in ongoing clinical trials of immune-mediated, inflammatory, and degenerative diseases $[1,2]$. A sine-qua-non to enhance the effectiveness of MSC therapy is the understanding of their biology and mechanisms of action, as well as those approaches which potentiate desired MSC functions [3, 4].

MSCs display limited engraftment or persistence capacity at sites of injury [5-7]. The functional improvements post-MSC infusion are in part mediated by paracrine mechanisms (e.g., cytokines, chemokines, and growth factors) which modulate the MSC microenvironment and influence the activity of resident cells [8]. In fact, MSC-conditioned media (MSC CM) recapitulates many effects of MSCs and is an alternative to the use of cell therapy [9-13]. The MSC secretome is highly dynamic due to its ability to sense and respond to environmental cues [14]. For example, pro-inflammatory cytokines (e.g., IFN- $\gamma$, TNF- $\alpha$, IL-1) change the content of immunomodulatory factors secreted by MSCs (e.g., TSG-6, PGE 2 , HGF, TGF- $\beta 1$, and IL-10) [15-17]. Hypoxic conditions, on the other hand, stimulate MSCs to secrete pro-angiogenic factors (e.g., IGF-1, TGF- $\beta 1$, VEGF, angiogenin, EGF, and bFGF) [18].

Extracellular vesicle (EV) production is an evolutionarily conserved process fundamental for the removal of intracellular "surplus" molecules and for intercellular communication $[19,20]$. Secreted EVs carry complex assemblies of bioactive factors (i.e., cargo) such as lipids, proteins (transcription factors, growth factors, and enzymes), nucleic acids (RNAs: mRNAs, microRNAsmiRNAs, and non-coding RNAs-lncRNAs; and DNA: ssDNA and dsDNA), and in some cases components of organelles (e.g., mitochondrial DNA) [21, 22]. EVs are heterogeneous and so are the emerging pathways of their biogenesis with the emerging roles of endosomal sorting complex required for export (ESCRT), GTPases (RAB7, RAB11, RAB27A, RAB27B), sphingomyelinases (SPMD3), tetraspanins (CD63, CD81), and other mechanisms [21]. Upon uptake, the EV cargo modulates the activity of recipient cells [23-25]. EVs secreted by MSCs (MSC-EVs) are a promising therapeutic component of the MSC secretome [26]. Most preclinical studies involving MSC-EV therapy are based on vesicles produced by resting MSCs $[27,28]$. Little is known about how the local microenvironment influences MSC vesiculation.

The functional properties of MSCs are influenced by the donor's age and age-associated diseases (e.g., atherosclerosis, type 2 diabetes) [29, 30]. We showed that these characteristics alter the secretome and reduce the immunosuppressive ability of MSCs [29, 30]. In addition, multiple plasma EV populations associated with immune cells decline with aging, while ageassociated chronic diseases may additionally alter EV production [31-33], but rigorous studies involving MSC-EVs are lacking. In this study, we addressed the effects of cytokine priming and donor age on human ATMSC vesiculation. We showed that cytokine priming upregulates RAB27B, increasing the secretion of small EVs (sEVs; <200 nm) containing A20 and TSG-6, key mediators of MSC immunopotency. Accordingly, these EVs inhibit $\mathrm{T}$ cell proliferation in a dose-dependent manner. We also found that MSCs from young donors display higher $R A B 27 B$ expression and secrete more sEVs relative to MSCs from older donors. Our study suggests that, cytokine priming and aging impact the quantity and cargo of MSC-EVs, thus these factors need to be considered in preparing EVs for clinical trials.

\section{Methods \\ Study subjects}

This study was approved by the McGill University Health Center Ethics Review Board (Protocol 10-107). All participants provided written informed consent. Subcutaneous adipose tissue was obtained from 9 pediatric (Ped; $16.1 \pm 2.6$ years) and 14 adult donors (Ad; $62.6 \pm$ 12.7 years). Table S1 summarizes the demographic characteristics of the study participants.

\section{Human AT-MSC isolation and expansion}

Human AT-MSCs were isolated and expanded as previously described and characterized according to the minimal definition criteria suggested by the International Society for Cellular Therapy (ISCT) [29, 34] (Fig. S1). Briefly, human subcutaneous adipose tissue samples were washed with phosphate-buffered saline (PBS), minced with surgical scissors, and digested with 0.05\% collagenase (Millipore Sigma) in Hank's balanced salt solution (HBSS) (Invitrogen). The enzyme was then neutralized with $5 \% \mathrm{Gibco}^{\circ} \mathrm{MSC}$ Qualified fetal bovine serum (FBS; Thermo Fisher Scientific). Dissociated cells were collected by centrifugation $\left(4{ }^{\circ} \mathrm{C}, 800 \mathrm{~g}\right.$ for $\left.5 \mathrm{~min}\right)$ and re-suspended in complete medium $(1.0 \mathrm{~g} / \mathrm{L}$ glucose, with L-glutamine and sodium pyruvate Dulbecco's modified Eagle's medium [DMEM; WISENT Inc.]) supplemented with $10 \%$ FBS and $1 \%$ penicillin/streptomycin $(10,000$ units $/ \mathrm{mL}$ penicillin, $10,000 \mathrm{mg} / \mathrm{mL}$ streptomycin, WISENT Inc.). MSCs were seeded at $1 \mathrm{~g}$ of tissue/flask and cultured under standard conditions (5\% carbon dioxide, $37^{\circ} \mathrm{C}$ ) in $75-\mathrm{cm}^{2}$ tissue culture flasks. Two days after the initial isolation, non-adherent-cells were washed off and complete media was replaced. When 
MSCs reached $80 \%$ confluency, they were detached with $0.25 \%$ Trypsin-EDTA $\left(37^{\circ} \mathrm{C}\right.$ for $\left.5 \mathrm{~min}\right)$ and re-seeded at a density of 5000 cells $/ \mathrm{cm}^{2}$. Passage 1 MSCs were stored in liquid nitrogen. Passage 4 MSCs were used for all experiments.

\section{MSC CM preparation}

MSCs $\left(2.5 \times 10^{5}\right.$ cells $\left./ \mathrm{ml}\right)$ were preconditioned/primed for $72 \mathrm{~h}$ with IFN- $\gamma$ (10 ng/mL, R\&D Systems) and TNF$\alpha(15 \mathrm{ng} / \mathrm{mL}, \mathrm{R} \& D$ Systems $)$ as suggested by the ISCT [35]. MSC CM was prepared in EV collection media [phenol red-free low-glucose DMEM containing 1\% insulin-transferrin-selenium (ITS; Thermo Fisher Scientific)]. This media did not contain serum (e.g., fetal bovine serum-FBS) to avoid contamination with serum microparticles [36]. Resting MSCs (not primed with cytokines) served as controls. After removing cells and debris by centrifugation, MSC CM were stored at $80^{\circ} \mathrm{C}$.

\section{MSC immunopotency assay}

Peripheral blood mononuclear cells (PBMCs) were isolated from one healthy donor (26 years old female) with Lymphocyte Separation Medium (Mediatech, Inc.) through density gradient centrifugation. PBMCs were stained with carboxyfluorescein succinimidyl ester (CFSE; Millipore Sigma) and stimulated with Concanavalin A (ConA; $10 \mu \mathrm{g} / \mathrm{ml})$ in Rosewell Park Memorial Institute medium (RPMI-1640) (WISENT Inc.) supplemented with 10\% FBS and 1\% Penicillin Streptomycin. CFSE-stained and ConA-activated PBMCs $(2 \times$ $10^{6}, 100 \mu \mathrm{l}$ ) were added to either (a) resting/primed MSC CM $(100 \mu \mathrm{l})$ or (b) MSC-EVs $(2$ or $4 \mu \mathrm{g}$ in $100 \mu \mathrm{l})$. Activated PBMCs cultured in EV collection media served as the positive control (maximal proliferationMax), while non-activated PBMCs served as a negative control (minimal proliferation-Min). After 4 days, the PBMCs were collected and stained with 7aminoactinomycin D (7-AAD, Cat\# 559925) and CD4APC (Cat\# 555349; BD Biosciences). The Expansion Index (EI) of $7 \mathrm{AAD}^{-} / \mathrm{CD}^{+}$cells (viable $\mathrm{CD} 4^{+} \mathrm{T}$ cells) was determined with FlowJo software. The proliferation of $\mathrm{CD}^{+} \mathrm{T}$ cells was calculated using the following formula:

$$
\begin{aligned}
& \text { CD4 }^{+} \text {T cell proliferation }(\%) \\
& =\frac{(x-\text { Min })}{\operatorname{Max}-\operatorname{Min}} \times 100 \%
\end{aligned}
$$

where $x=\mathrm{EI}$ of stimulated $\mathrm{CD}^{+} \mathrm{T}$ cells in the presence of MSC or derived products; Min =EI of nonstimulated $\mathrm{CD}^{+} \mathrm{T}$ cells; and $\mathrm{Max}=\mathrm{EI}$ of stimulated $\mathrm{CD} 4^{+} \mathrm{T}$ cells in the absence of MSCs.

\section{Collection of EVs from MSC CM}

EVs were obtained from MSC CM as previously described with some modifications [37] and were characterized according to recommendations of the International Society for Extracelular Vesicles (ISEV) [20]. MSCs were grown in T75- $\mathrm{cm}^{2}$ flasks with complete medium until they reached $80 \%$ confluency. MSCs were then washed with PBS and cultured an additional 3 days in EV collection medium with or without cytokines for priming. Cells and debris were eliminated from the CM by centrifugation at $800 \mathrm{~g}$ for $5 \mathrm{~min}$ and $2000 \mathrm{~g}$ for 10 min. The CM was then filtered using $0.22-\mathrm{mm}$ pore filters (Millipore Sigma) to eliminate large EVs. EVs were then harvested from the filtered CM by ultracentrifugation at 110,000 $\mathrm{g}$ (Type $70 \mathrm{Ti}$ fixed angle, Beckman Coulter) for $2 \mathrm{~h}$ at $4{ }^{\circ} \mathrm{C}$. The pellet was washed in $18 \mathrm{ml}$ of PBS prior to a second ultracentrifugation step $\left(4^{\circ} \mathrm{C}\right.$, $110,000 \mathrm{~g}$ for $2 \mathrm{~h}$ ) and re-suspended in $100 \mu \mathrm{l}$ of PBS. Samples were stored in $10 \mu \mathrm{l}$ aliquots at $-80^{\circ} \mathrm{C}$ to avoid freeze thawing.

\section{Nanoparticle tracking analysis}

The size and concentration of nanoparticles in MSC CM and EV preparations was measured using NanoSight NS500 (NanoSight) [38]. PBS was used to dilute MSC CM (1:12) and EV preparations (1:100-500) to achieve 40-100 particles per frame during quantification. Five 30 -s videos were obtained at room temperature for each sample.

\section{Quantitative PCR-MSC vesiculation}

The expression of genes linked to cellular vesiculation was analyzed in resting and primed MSC $(n=6$ per group) by real-time PCR using a custom $\mathrm{RT}^{2}$ Profiler PCR Array (SABiosciences, Qiagen) as previously described [39]. P4 MSCs were expanded in $75-\mathrm{cm}^{2}$ flasks to $80 \%$ confluence in complete medium, washed with PBS, and cultured for an additional $72 \mathrm{~h}$ in EV collection medium with or without cytokine priming. TRIzol reagent (Thermo Fisher Scientific) was used as a lysis buffer to extract total RNA from MSC. Purified RNA was obtained using Direct-zol ${ }^{\mathrm{m}}$ RNA MiniPrep (Zymo Research) and quantified using BioDrop $\mu$ lite spectrophotometer (Harvard Bioscience, Holliston, MA). Reverse transcription (RT) was performed using $1 \mu \mathrm{g}$ of purified RNA and QuantiTect reverse transcription kit (Qiagen) according to manufacturer's instructions. Following RT, the complementary deoxyribonucleic acid (cDNA) was combined with $\mathrm{RT}^{2}$ SYBR Green qPCR Master Mix (SABiosciences, Qiagen), and $25 \mu \mathrm{l}$ of this mix was loaded per well of the custom $\mathrm{RT}^{2}$ Profiler PCR Array. Quantitative real-time PCR was performed using LightCycler 96 System software (Roche Molecular Systems) as follows: a 10 -min activation step $\left(95^{\circ} \mathrm{C}\right)$, followed by 
a two-step amplification step for 45 cycles $\left(15 \mathrm{~s}\right.$ at $95^{\circ} \mathrm{C}$ and $1 \mathrm{~min}$ at $60^{\circ} \mathrm{C}$ ), and a final thermal dissociation step $\left(95^{\circ} \mathrm{C} 10 \mathrm{~s}, 65^{\circ} \mathrm{C} 60 \mathrm{~s}, 97^{\circ} \mathrm{C} 1 \mathrm{~s}\right)$. The relative expression of EV-related genes was normalized to the expression of three housekeeping genes (ACTB, GAPDH, YBX1) and calculated using the $\Delta \Delta \mathrm{Ct}$ method by Schmittgen and Livak [40]. Statistical differences between resting and primed MSCs were determined using 2-way ANOVA with Bonferroni's correction for multiple comparisons.

\section{Iodixanol/Optiprep gradient}

EV density was assessed using an Iodixanol/Optiprep gradient protocol [41]. Briefly, to assess the density of isolated EVs, EV preparations were loaded in a gradient

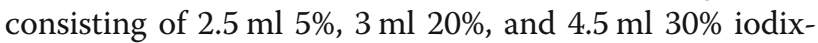
anol (OptiPrep ${ }^{\mathrm{m}}$ Density Gradient Medium, Millipore Sigma) prepared in diluent $(0.25 \mathrm{M}$ sucrose, $150 \mathrm{mM}$ $\mathrm{NaCl}, 20 \mathrm{mM}$ HEPES, pH 7.4). The gradient was separated by ultracentrifugation in an SW-41 Ti rotor (Beckman Coulter) $\left(4{ }^{\circ} \mathrm{C}, 200,000 \mathrm{~g}\right.$ for $\left.2 \mathrm{~h}\right)$. One milliliter fractions were collected from which $8 \mu \mathrm{l}$ was retained for NTA. Using a refractometer, the index of refraction for each fraction was measured in the control gradient. Densities were calculated according to the manufacturer's instructions.

\section{Transmission electron microscopy of MSC-EVs}

TEM images of MSC-EVs were obtained as previously described [42]. Briefly, EVs purified by ultracentrifugation were suspended in EV buffer $(137 \mathrm{mM} \mathrm{NaCl}, 20$ mM HEPES, pH 7.5) and fixed onto carbon-coated grids with glutaraldehyde. After fixation, the grids were stained with uranyl acetate and imaged using TEM.

\section{Western blot}

MSC lysates $\left(10^{7} \mathrm{MSC} / \mathrm{mL}\right)$ were prepared in RIPA buffer $(50 \mathrm{mM}$ Tris- $\mathrm{HCl}, 150 \mathrm{mM} \mathrm{NaCl}, 1 \% \mathrm{NP}-40,0.5 \%$ sodium deoxycholate, and 0.1\% SDS, $\mathrm{pH}$ 7.4; Boston Bioproducts) and $1 \times$ Protease Arrest ${ }^{\mathrm{Tm}}$ (G-Biosciences). The protein concentrations of cell lysate, $\mathrm{CM}$ and $\mathrm{EV}$ preparations were quantified using Micro $\mathrm{BCA}^{\mathrm{Tw}}$ Protein Assay Kit (Thermo Fisher Scientific). Fifty micrograms of MSC lysate, MSC CM, MSC-EV, and Page Ruler ${ }^{\mathrm{Tm}}$ Prestained Protein Ladder (Thermo Fisher Scientific) were loaded into a standard 12\% SDS-PAGE and transferred to a PVDF membrane. The membrane was probed with antibodies against CD81 (Thermo Fisher Scientific), ALIX (Santa Cruz Biotechnology), calnexin (Abcam), TSG-6 (Santa Cruz Biotechnology), A20 (Cell Signaling Technology), or GAPDH (Santa Cruz Biotechnology); followed by specific IgG horseradish peroxidase-conjugated antibodies (Jackson ImmunoResearch Labs). Immunoreactive proteins were visualized with Amersham ${ }^{\text {Ts }}$ ECL Prime Western Blotting Detection
Reagent (GE Healthcare Life Sciences) and imaged using Omega Lum ${ }^{\mathrm{Tx}} \mathrm{C}$ Imaging System (Aplegen ${ }^{\circ}$ ).

\section{Proteomic analysis of MSC-sEVs}

Proteomic analysis of MSC-sEVs was performed by the Proteomics Platform of The Research Institute of the McGill University Health Centre (RI-MUHC). For each resting or primed MSC-sEV preparation ( $n=3$ for each group, $5 \mu \mathrm{g}$ per sample), a single stacking gel band was reduced with DTT, alkylated with iodoacetic acid, and then digested with trypsin. Peptides were re-solubilized in $0.1 \%$ aqueous formic acid $/ 2 \%$ acetonitrile, loaded onto a Thermo Acclaim Pepmap (Thermo, $75 \mu \mathrm{M}$ ID $\times 2 \mathrm{~cm}$ C18 $3 \mu \mathrm{m}$ beads) precolumn, and then onto an Acclaim Pepmap Easyspray (Thermo, $75 \mu \mathrm{M} \times 15 \mathrm{~cm}$ with $2 \mu \mathrm{m}$ C18 beads) analytical column separation using a Dionex Ultimate $3000 \mathrm{uHPLC}$ at $220 \mathrm{~nL} / \mathrm{min}$ with a gradient of $2-35 \%$ organic ( $0.1 \%$ formic acid in acetonitrile) over 3 h. Peptides were analyzed with a Thermo Orbitrap Fusion mass spectrometer operating at a 120,000 resolution (FWHM in MS1, 15,000 FWHM for MS/MS) with HCD sequencing of all peptides with a charge of $2+$ or greater. The raw data was converted into ".mgf format (Mascot generic format), searched using Mascot 2.3 against human sequences (Swissprot 2017). The database search results were loaded onto Scaffold Q+ Scaffold_4.7.2 (Proteome Sciences) for spectral counting statistical treatment and data visualization. Classification of MSC small exosome-like EV cargo by Gene Ontology (GO) cellular component and biological process was performed using the Database for Annotation, Visualization and Integrated Discovery (DAVID) of the National Institute of Allergy and Infectious Disease (http://david.abcc. ncifcrf.gov). Proteomic datasets are freely available upon request to the corresponding author.

\section{MSC RAB27B silencing}

$R A B 27 B$ siRNA (Accell Smart pool, E-004228-00-0005, Dharmacon) was used for gene knockdown in MSC according to the manufacturer's instructions. Nontargeting siRNA (Accell Non-targeting Pool, D-00191010, Dharmacon) were used for siRNA control. Briefly, $5 \times 10^{3}$ MSC were seeded in each well of a 96-well plate with complete medium overnight prior to incubation with $100 \mu \mathrm{L}$ of each siRNA mixture $(1 \mu \mathrm{M})$ diluted in EV collection medium. After $24 \mathrm{~h}$, the supernatant was discarded, and the cells were washed with PBS before incubation with EV collection medium with or without IFN$\gamma(10 \mathrm{ng} / \mathrm{mL})$ and TNF- $\alpha(15 \mathrm{ng} / \mathrm{mL})$ for $72 \mathrm{~h}$.

\section{Statistical analysis}

All statistical analyses were performed with GraphPad Prism software (GraphPad Prism 8) and presented as bar graphs. Non-parametric tests (Mann-Whitney or 
Wilcoxon signed-rank test) were used for between groups' comparisons. All hypotheses tests were 2-sided. A $p$ value of $<0.05$ was considered statistically significant.

\section{Results}

Cytokine priming enhances the immunopotency and increases exosome-like EV release by MSCs

In order to quantitatively evaluate the effect of cytokine priming on the immunopotency of the MSC secretome, we designed an in vitro assay the sensitivity of which allowed us to test the immunosuppressive ability of MSC CM against T cell targets (section "MSC immunopotency assay"). Using this approach, we observed that IFN- $\gamma$ and TNF- $\alpha$-priming enhanced the capacity of ATMSC CM to suppress the proliferation of activated $\mathrm{CD}^{+} \mathrm{T}$ cells compared to $\mathrm{CM}$ from resting MSCs (Fig. 1a-b). Of relevance, MSC priming did not alter $\mathrm{CD}^{+}{ }^{+} \mathrm{T}$ cell viability (Fig. 1c).

Because the biological activity of MSC secretome is often attributed to the EV content, we assessed the effect of MSC cytokine priming on EV release by comparing the size distribution and concentration of nanoparticles in the MSC CM using nanoparticle tracking analysis (NTA). Following priming, the number of small particles significantly increased in MSC CM (Fig. 2a,b). This effect required a combined presence of both IFN- $\gamma$ and TNF- $\alpha$ and was not observed when each of these cytokines was used alone (Fig. S2). Since NTA cannot distinguish protein aggregates, or solid particles from EVs, this analysis was repeated following purification of MSC-EVs by differential centrifugation [37]. Once again, higher numbers of events were observed in the pelleted $\mathrm{CM}$ fraction expected to contain small EVs (sEV) and collected by ultracentrifugation $(100,000 \times g=100 \mathrm{~K})$ of primed MSCs versus their resting controls (Fig. 2c,d). No significant changes were observed in MSC viability after cytokine priming, suggesting that the SEVs were not apoptotic/necrotic fragments or cell debris (Fig. S3).

In order to explore possible reasons for the increase in primed MSC vesiculation, we performed a comparative targeted gene expression analysis. Resting and primed MSCs were screened for mRNA levels of EV biogenesisrelated genes including ESCRT machinery, Rab GTPases, and tetraspanins (Fig. 2e) [39]. Compared to resting MSCs, $R A B 27 B$ and $C D 82$ were the only two genes highly upregulated in primed MSCs (19.6-fold and 21.5fold respectively). The fact that primed MSCs upregulated $R A B 27 B$, and increased the secretion of sEVs with a density of $1.13 \mathrm{~g} / \mathrm{mL}$ (section "Primed MSC-EVs carry unique immunomodulatory proteins and inhibit $\mathrm{T}$ cell proliferation"), suggest that priming may stimulate biogenesis of particles that resemble and include exosomes [43]. Thus, cytokine priming stimulates the immunomodulatory properties of the MSC secretome along with its SEV content and activity of the vesiculation pathway.

\section{(a)}
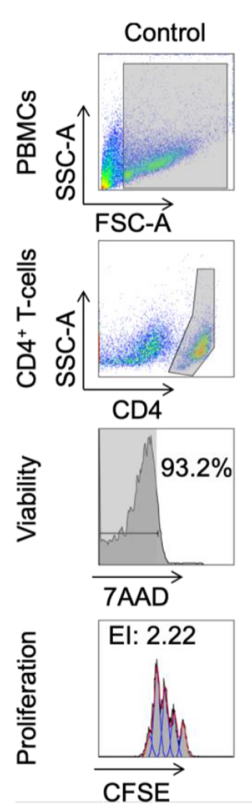
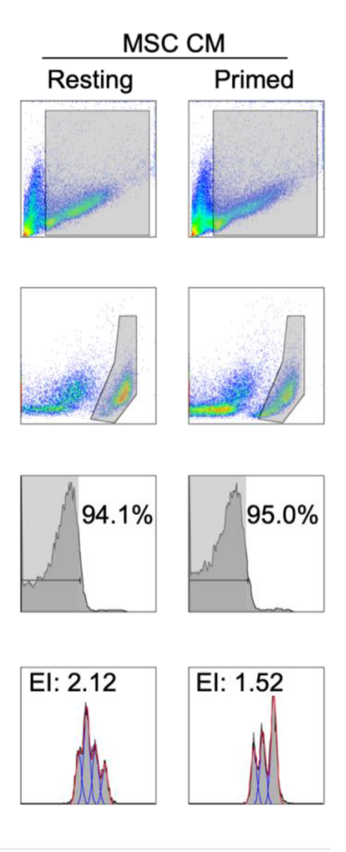

(b)

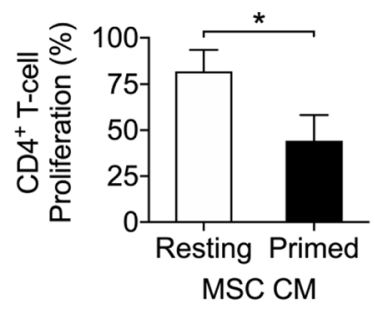

(c)

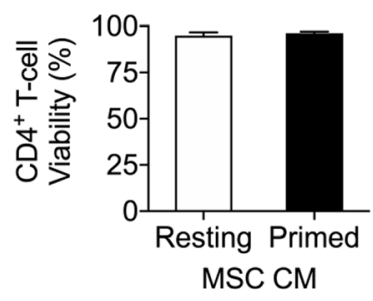

Fig. 1 Cytokine priming enhances the ability of MSC-conditioned media (MSC CM) to suppress T cell proliferation. a ConA-stimulated T cell proliferation assay with resting and primed MSC CM (representative example). Gating strategy and Expansion Index (EI) of viable CD4 ${ }^{+} \mathrm{T}$ cells cultured with media conditioned by resting or primed MSC. $\mathbf{b}$ Summary graph of ConA-stimulated CD4 ${ }^{+} \mathrm{T}$ cell proliferation and $\mathbf{c}$ viability in the presence of resting or primed MSC CM. Wilcoxon signed-rank test, mean \pm SD of 6 independent samples are reported, $\left(^{*}\right)$ represents $p \leq 0.05$ 


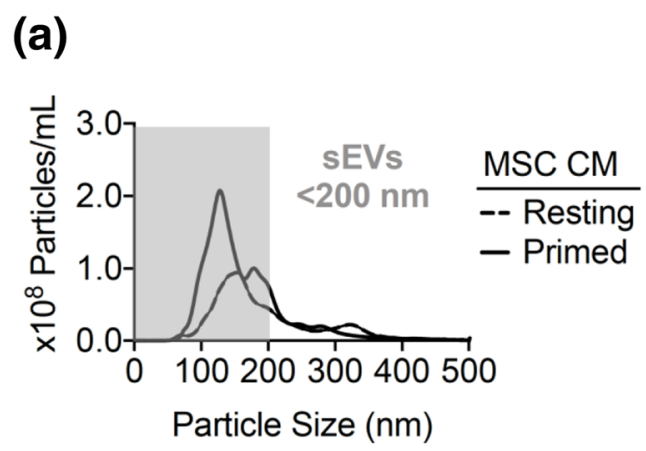

(b)

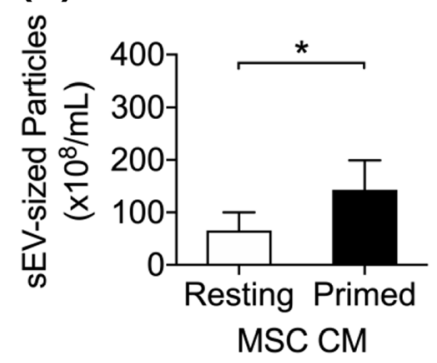

(c)

(d)
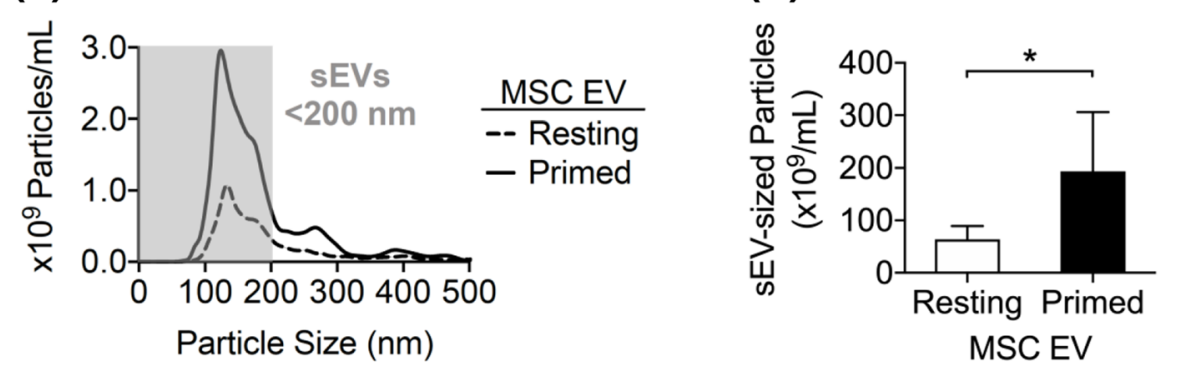

(e)

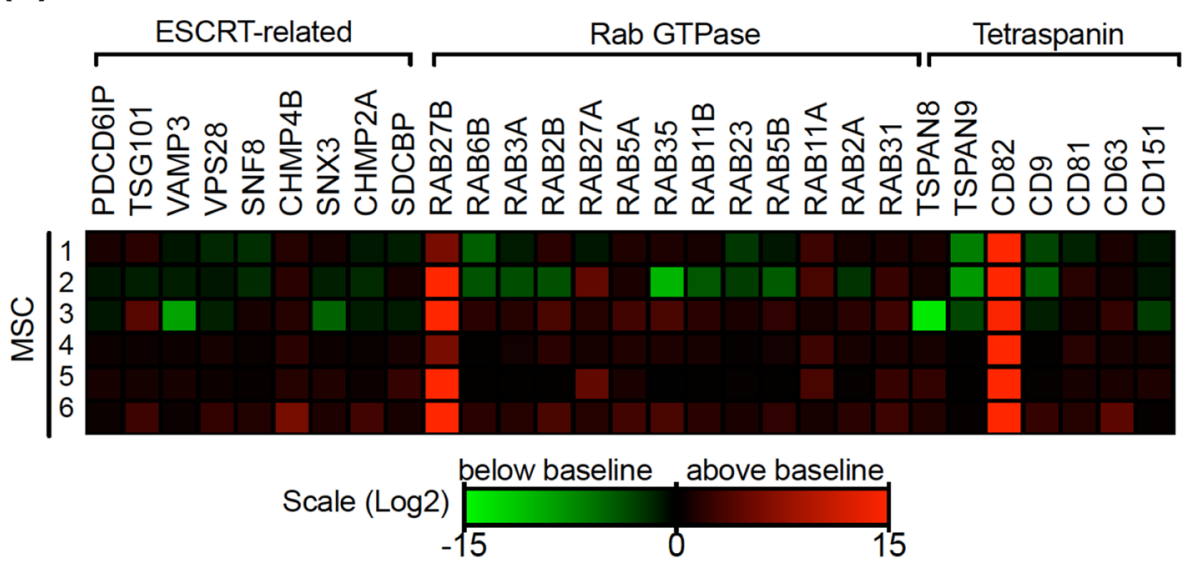

Fig. 2 Cytokine priming increases MSC-sEV release. a Particle concentration and size distribution of resting and primed MSC CM. Curves represent the average of 6 independent samples. The gray box indicates small EV (sEV)-sized particles $(<200 \mathrm{~nm})$ as defined by ISEV. b Quantity of sEV-sized particles in resting and primed MSC CM. c Particle concentration and size distribution of EVs collected by filtration and ultracentrifugation of resting and primed MSC CM (curves represent average of 6 independent samples, gray box highlights sEV-sized particles). d Quantity of sEV-sized particles in EVs collected from resting and primed MSC CM. e Heatmap of vesiculation genes differentially expressed upon MSC priming. Samples 1,2 , and 3 are from pediatric MSC donors and the rest from adult MSC donors. Data represents fold change relative to resting MSC. Increased expression (red) and reduced expression (green) are shown on a log2-based scale. Wilcoxon signed-rank test, mean \pm SD of 6 independent samples are reported, $(*)$ represents $p \leq 0.05$

To understand the nature of cytokine stimulating EV release, we further extended our EV characterization. First, EVs from primed and resting MSC CM were analyzed according to recommendations from the International Society for Extracellular Vesicles (ISEV) to ascertain that they meet essential EV characteristics [36, 44]. Indeed, a more detailed NTA sizing revealed that primed MSC-EVs were mainly below $200 \mathrm{~nm}$ and they floated at a density of 1.13 $\mathrm{g} / \mathrm{mL}$ in an iodixanol gradient (Fig. 3a,b). In transmission electron microscopy (TEM), MSC-sEVs appeared homogeneous in size $(50-100 \mathrm{~nm})$ and displayed cup-like morphology observed following fixation of small vesicles such as exosomes (Fig. 3c). The presence of proteins typically enriched in EVs (i.e., the ESCRT-associated protein ALIX and tetraspanin CD81), and the absence of proteins present in other organelles (i.e., the endoplasmic reticulum protein calnexin) were confirmed by Western blot and indicated the purity of the MSC-EV preparations 
(a)

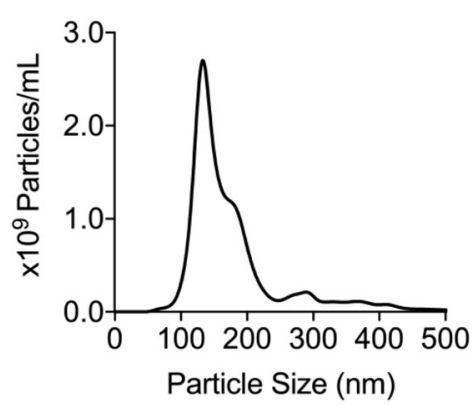

(c)

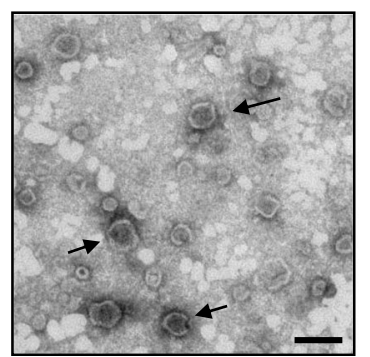

(b)

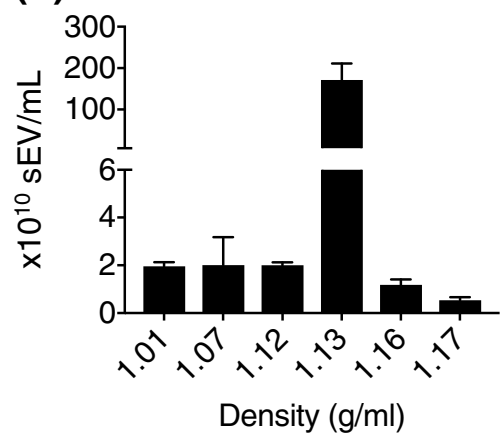

(d)

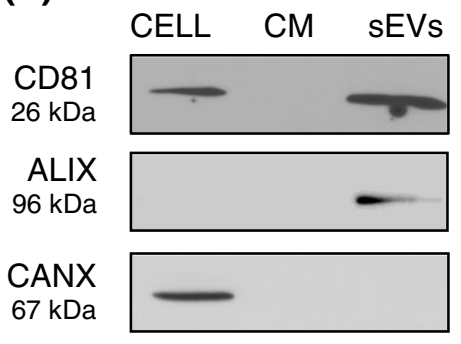

Fig. 3 Characterization of cytokine-primed MSC-sEVs. a Nanoparticle tracking analysis (NTA) of primed MSC-sEVs. b NTA of MSC-sEV flotation densities following fractionation with iodixanol density gradient. c Transmission electron microscopy of negative stained MSC-sEVs. Scale bar represents $100 \mathrm{~nm}$. d Western blot analysis of MSC cell extracts (CELL), conditioned media (CM), and small exosome-like EVs (sEVs) for EV-enriched proteins (CD81, ALIX) and major contaminant protein derived from subcellular organelles such as endoplasmic reticulum (CANX, calnexin)

(Fig. 3d). Importantly, nanoparticle flow cytometry confirmed that tetraspanins CD63 and CD81 were coexpressed on primed MSC-EVs, a feature associated with endosome-derived EV (Fig. S4) [45]. The MSC marker CD90 but not CD73 was identified on MSC-sEVs, as previously described [46]. Altogether, this data documents that IFN- $\gamma$ and TNF- $\alpha$ promote MSC release of exosomelike sEVs carrying canonical MSC markers.

\section{Primed MSC-EVs carry unique immunomodulatory proteins and inhibit $\mathrm{T}$ cell proliferation}

The cargo of cytokine-primed and resting MSC-sEVs was assessed by mass spectrometry. In total, 380 proteins were identified in at least two of three samples from each group. Thirty-six of the proteins identified were only present in resting MSC-sEVs, while 183 were unique to primed MSC-sEVs. A total of 161 proteins were shared by sEVs from both groups (Fig. 4a). Analysis of cellular compartments and biological functions associated with the shared proteins and unique proteins was performed using DAVID Functional Annotation Tool. The majority of the proteins $(80 \%, 129 / 161)$ shared between resting and primed MSC-sEVs were associated with extracellular sEVs. Among these, 19 proteins were listed in ExoCarta's top 100 proteins that are often identified in exosomes (http://exocarta.org/sEV_markers_ new). These included tetraspanins (CD63, CD81), flotillins (FLOT1), MFGE8, ALIX (PDC6IP), syntenin-1 (SDCBP), annexins (ANXA1, ANXA2, ANXA5, ANXA6), heat shock proteins (HSP90, HSPA8), and transferrin receptor (TFRC) (Fig. 4b). Proteins shared by resting and primed MSC-sEVs were involved in functions including, but not limited to, extracellular matrix organization, cell adhesion, proteolysis, receptormediated endocytosis, and angiogenesis.

Of the proteins uniquely identified in primed MSCsEVs, the majority were associated with extracellular sEVs $(80 \%, 147 / 183)$. In total, 17 of these proteins were listed in ExoCarta's top 100 proteins found in exosomes, albeit different than those for resting MSCs. Of relevance, primed MSC-sEVs contained CD82, ESCRT-associated proteins (CHMP4B, TSG101), heat shock proteins (HSPA5, HSP90AB1), adhesion molecules (ICAM1), Rab GTPases (RAB5C, RAB7A), and lysosomal-associated membrane proteins (LAMP1, LAMP2). The unique proteins were associated with a wide range of biological processes, including, but not limited to, inflammatory response, antigen processing and presentation, cell adhesion, rRNA processing, and translation (GO biological process ontologies) (Fig. 4c). Among proteins involved in the inflammatory response, we identified candidate proteins implicated in MSC immunopotency. Among those, A20 [i.e., tumor necrosis factor-a-induced protein 3 (TNFAIP3)] and TSG-6 
(a)

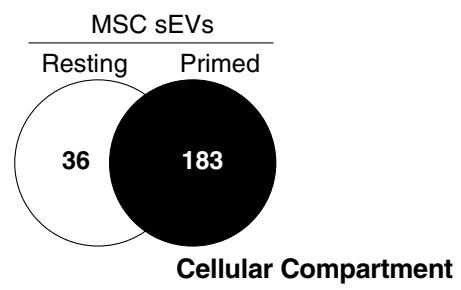

(b)

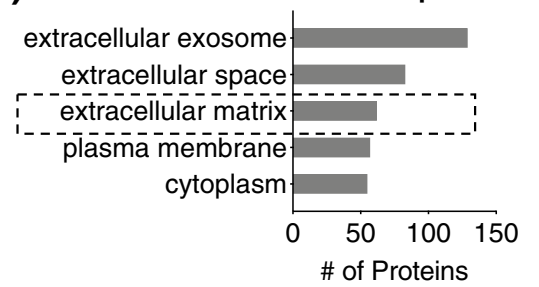

sEVs-Enriched Proteins

$\begin{array}{ccc}\text { EVs-Enriched Proteins } & \\ \text { CD63 } & \text { GNAI2 } & \text { MSN } \\ \text { CD81 } & \text { HSP90 } & \text { PDC6IP } \\ \text { ENO1 } & \text { HSPA8 } & \text { SDCBP } \\ \text { FLOT1 } & \text { LGALS3BP } & \text { TFRC } \\ \text { GAPDH } & \text { MFGE8 } & \end{array}$

(d)

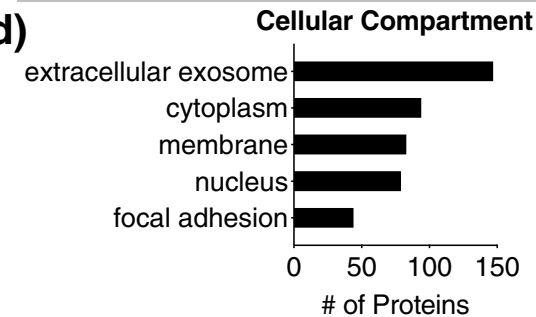

\begin{tabular}{lcccc}
\multicolumn{5}{c}{ sEVs-Enriched Proteins } \\
ACLY & CD82 & HSP90AB1 & LAMP2 & TSG101 \\
CCT2 & CHMP4B & HSPA5 & RAB5C & \\
CCT3 & CLTC & ICAM1 & RAB7A & \\
CCT5 & FASN & LAMP1 & TCP1 &
\end{tabular}

\section{(f)}

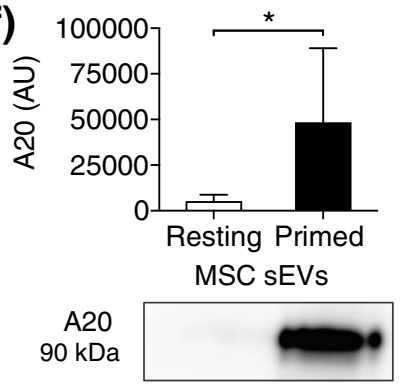

(c)

extracellular matrix

Biological Process

organization

cell adhesion.

proteolysis

receptor-mediated endocytosis

angiogenesis

\begin{tabular}{l:} 
MSC Markers \\
ENG \\
THY1 \\
NT5E \\
CD44 \\
\hdashline
\end{tabular}

(e)

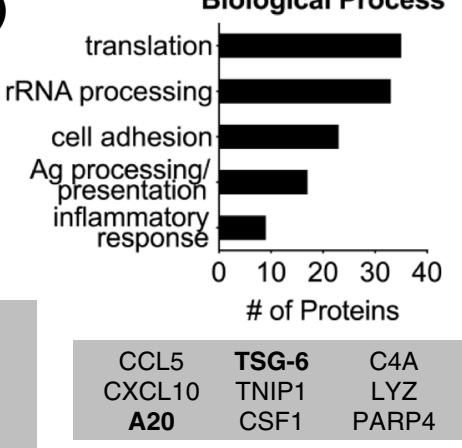

(g)

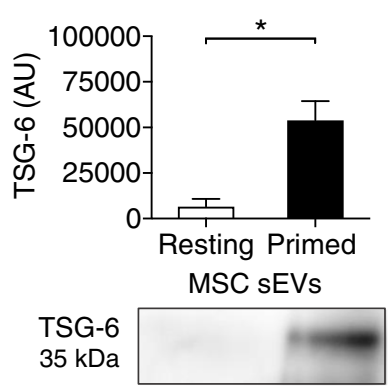

Fig. 4 sEVs from cytokine-primed MSCs contain immunomodulatory proteins. a Unique and common proteins in sEVs collected from resting and primed MSC CM ( $n=3$ per group). The graph includes proteins identified in at least two samples per group. $\mathbf{b}$, $\mathbf{c}$ Gene ontology analyses of the 161 proteins shared between resting and primed MSC-sEVs. Cellular components are shown on the left panel (b) and biological processes on the right panel (c). Proteins associated with ExoCarta's top EV 100 proteins (http://exocarta.org), and MSC markers are listed in the boxes below (gray box lists extracellular exosome/sEV-enriched proteins and dotted line box MSC markers). d, e Cellular components (d, left panel) and biological processes (e, left panel) associated with the 183 proteins uniquely present in primed MSC-sEVs (Gene Ontology analyses). Gray box below panel (d) lists extracellular exosome/sEV-enriched proteins and gray box below panel (e) lists proteins in the "inflammatory response" category. $\mathbf{f}, \mathbf{g}$ Western blot analysis of TSG-6 (TNFAIP6) and A20 (TNFAIP3) in resting and primed MSC-sEVs $(n=6)$. Wilcoxon signed-rank test, mean \pm SD are reported, $\left.{ }^{*}\right)$ represents $p \leq 0.05$

(i.e., TNFAIP6) (Fig. 4d) were uniquely found in sEVs from primed MSCs and not in sEVs from their resting counterparts $[47,48]$. These proteins have not been previously reported in small exosome-like EVs from human AT-MSCs.
The immunopotency of primed MSC-sEVs was assessed in an in vitro $\mathrm{T}$ cell proliferation assay (Fig. 5a). Primed MSC-sEVs inhibited $\mathrm{CD}^{+} \mathrm{T}$ cell proliferation in a dose-dependent manner while they did not alter $\mathrm{T}$ cell viability (Fig. 5b,c). In summary, cytokine-primed AT- 
MSCs release sEVs containing TSG-6/A20, which suppress the proliferation of activated $\mathrm{T}$ cells in a dosedependent manner.

\section{RAB27B regulates the secretion of EVs and TSG- 6 by primed MSCs}

The role of $R A B 27 B$ on the release of sEVs by cytokineprimed MSCs was assessed in three independent experiments. $R A B 27 B$ expression was markedly reduced in primed MSCs after treatment with $R A B 27 B$ siRNA (Fig. 6a). This was associated with a reduction in the number of sEV-sized particles in primed MSC CM as determined by NTA (Fig. 6b,c). RAB27B silencing reduced TSG-6 levels in primed MSC CM (Fig. 6c). Since in the proteomic data TSG-6 was exclusively found in the cargo of primed MSC-sEVs, the results presented in Fig. 6 suggest that Rab27b may be responsible for cytokine-driven, EV-mediated release of this immunomodulatory effector.

\section{Primed adult MSCs secrete fewer MSC-sEVs than pediatric MSCs}

MSCs from older donors are less efficient at suppressing allogeneic $\mathrm{T}$ cell proliferation (i.e., have reduced immunopotency). This, in part, relates to the fact that they secrete higher levels of "senescence-associated" proinflammatory cytokines [29]. We examined if MSC donors' age also affects the secretion of cytokine-induced
sEVs. The expression of $R A B 27 B$ in primed adult MSCs was significantly lower than in pediatric MSCs (Fig. 7a). This was associated with a reduction in small exosomelike EV quantities in adult MSC CM (Fig. 7b). These results suggest that donor's age influences the EV pathway responses to IFN- $\gamma$ and TNF- $\alpha$ priming.

\section{Discussion}

A well-defined property of MSCs is their capacity to secrete soluble factors and EVs (i.e., MSC secretome) that recapitulate MSC's effects on immune responses, angiogenesis, and fibrosis $[14,29]$. The composition of the secretome varies according to the MSC source, donor, and activation state among other factors. However, the contribution of the individual components of the MSC secretome to the functional effects of these cells in vivo is unknown. A clear demonstration of the mechanisms that underlie MSC's immunomodulatory effects and those that lead to interindividual differences in biological function is key to optimizing clinical responses to MSC therapy.

Here, we studied the effect of cytokine priming on MSC-EV biogenesis, and the implication of those EVs in MSC immunopotency. Cytokine priming enhanced the immunomodulatory properties of human AT-MSC secretome and enriched it with sEVs. Using a similar mode of activation, a study on BM-MSCs found that IFN- $\gamma$ and TNF- $\alpha$ reduced the secretion of MSC-EVs

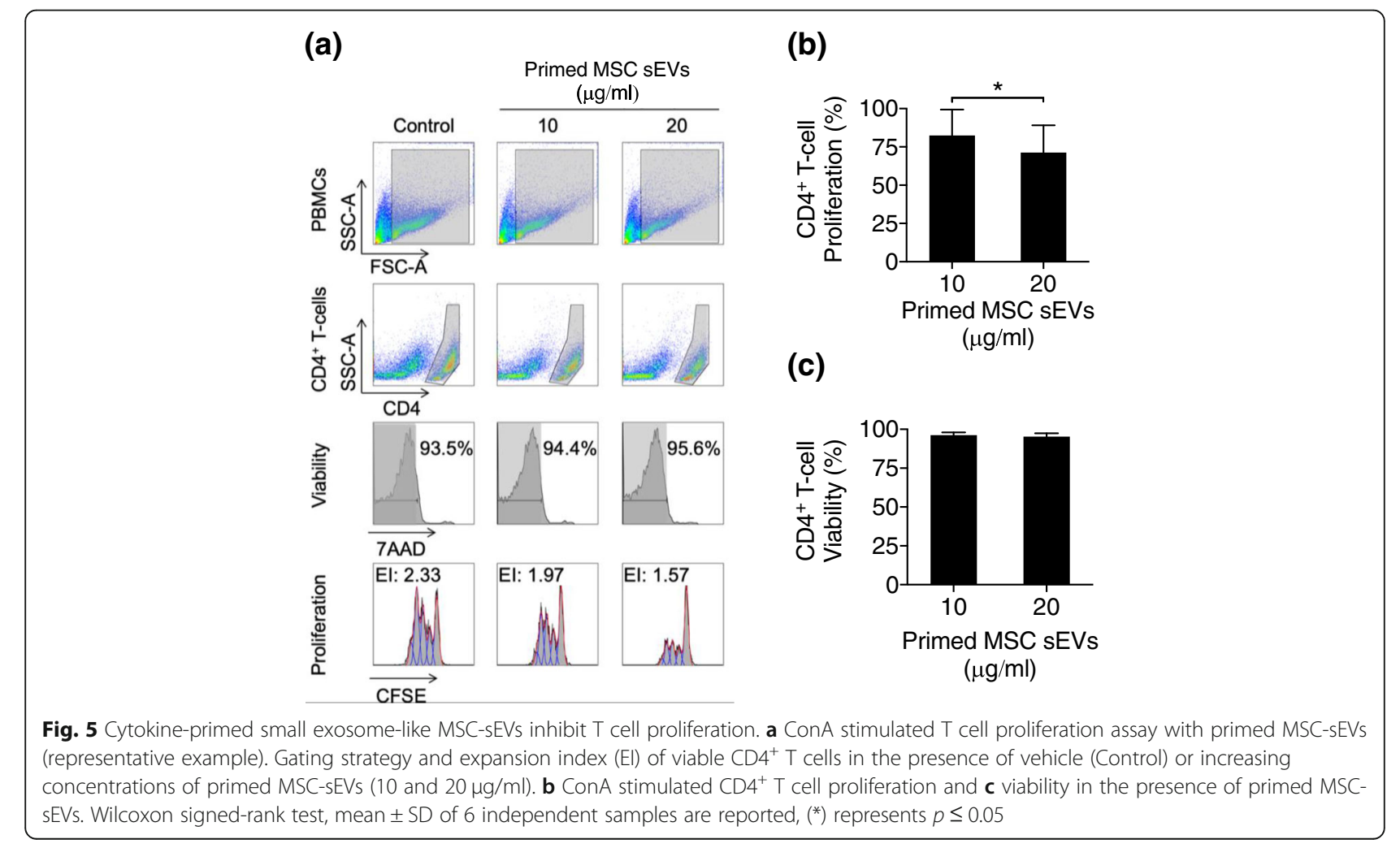




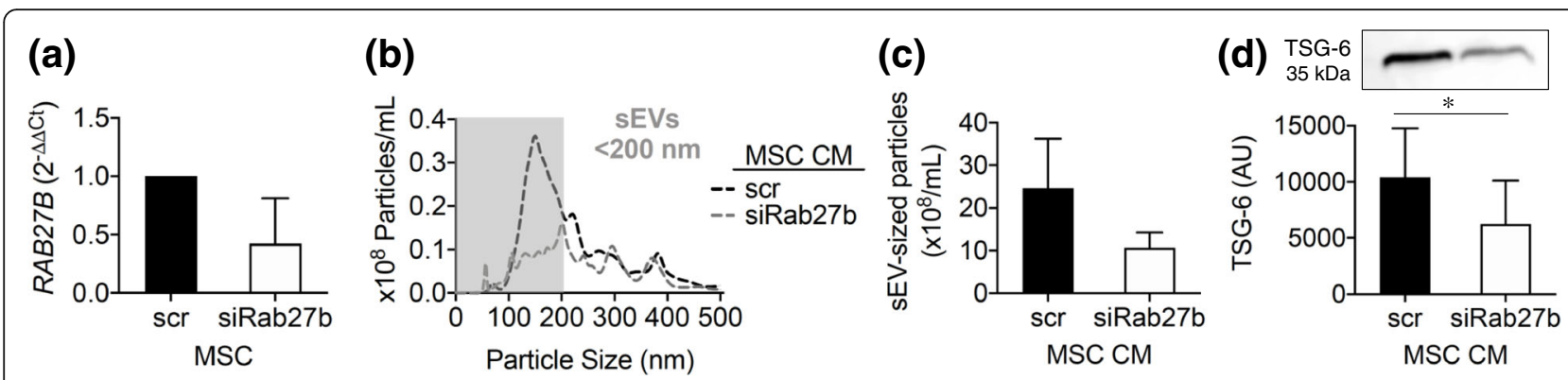

Fig. 6 RAB27B silencing reduces the secretion of TSG-6-enriched small exosome-like EVs by primed MS. a RAB27B expression in primed MSC treated with Rab27b siRNA (siRab27b) or scrambled (scr). b NTA of siRab27b and control MSC CM. c NTA of small EVs $(<200 \mathrm{~nm})$ and $\mathbf{d}$ Western blot of TSG-6 expression in CM from primed MSC treated with scr and siRab27b. In $\mathbf{b}$, curves represent the average of 3 independent samples. The gray box indicates small EV (sEV)-sized particles $(<200 \mathrm{~nm})$. In other panels, mean \pm SD of three individual samples are reported; $\mathbf{a}, \mathbf{c}$ nonsignificant differences between groups (paired $T$-test, $p=0.1, p=0.2$ respectively); in $\mathbf{d}{ }_{(*}^{*}$ ) represents $p \leq 0.05$

[46]. These contradictory results are likely explained by differences in the MSC tissue source and MSC-EV preparation. BM and AT-MSCs are not functionally equivalent. AT-MSCs have greater proliferative potential, secretion of cytokines, and immunomodulatory effects $[49,50]$. It is not known whether vesiculation mechanisms in AT and BM-MSCs differ. The absence of serum in our study may have also influenced the quantity and cargo of MSC-EVs, as it is known that nutrient status and cellular stress can influence sEV production $[51,52]$. For instance, glucose deprivation increases the quantity, repertoire of protein species, and angiogenic effects of cardiomyocyte sEVs [53]. The use of serum-free $\mathrm{EV}$ isolation media is key to prevent contamination with EVs present in FBS $[9,54,55]$. Moreover, FBS EVs contain RNA and can influence the activity of recipient cells [56]. Currently, there is no reliable method to completely eliminate EVs from FBS and therefore using serum-free media can be viewed as more conclusive.

The data we present support cytokine priming as a promising approach for generating bioactive AT-MSCsEVs (small EVs) for clinical applications. Primed MSCs significantly upregulated Rab27b. This small GTPase acts as the regulator of endosome trafficking that is implicated in the release of intraluminal vesicles from MVBs as exosomes [57]. We also identified a significant upregulation of the tetraspanin CD82 in primed MSCs, which is involved in exosomal secretion of signaling proteins such as $\beta$-catenin [58]. Thus, MSC priming may lead to release of immunomodulatory exosomes.

Recently, IL-1 $\beta$ priming was found to enhance the immunomodulatory properties of MSCs partially through sEV-mediated transfer of miR-146a in a mouse model of sepsis [59]. LPS stimulated MSCs to release sEVs (a)

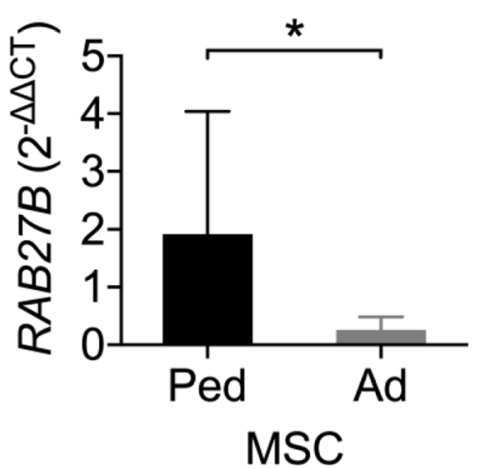

(b)

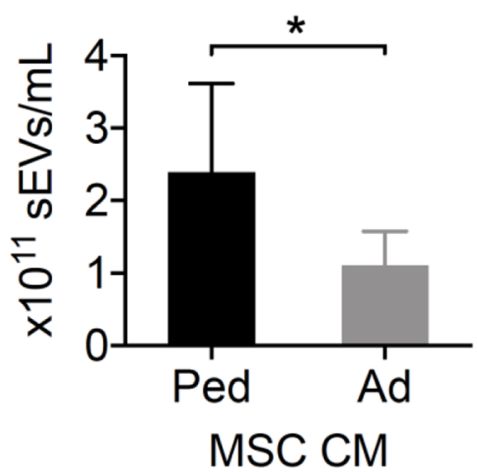

Fig. 7 Post-priming adult MSCs secrete less small exosome-like EVs than pediatric MSCs. a RAB27B expression of primed MSC and $\mathbf{b}$ NTA of sEVs in primed MSC CM from pediatric (Ped; $n=9)$ and adult (Ad; $n=9)$ donors. Mann-Whitney test, mean \pm SD are reported, where $(*)$ represents $p \leq 0.05$ 
containing let-7b, which improved the effects of MSCs on wound healing [60]. Further studies are needed to determine whether IFN- $\gamma$ and TNF- $\alpha$ priming of ATMSCs affects the RNA cargo of their sEVs in a manner relevant to their potential use as therapy for inflammatory conditions.

MSC-sEVs are proposed to act by delivering their cargo of proteins to the recipient cells [61]. Moreover, the MSC environment (e.g., hypoxic conditions) and specific interventions (e.g., radiation, nutrient starvation) impact the proteomic profile of MSC-EVs and, as a consequence, their functional effects [62-65]. Herein, we provide a detailed proteomic analysis of cytokineinduced sEVs enriched in small exosome-like EVs from human AT-MSCs. We demonstrate that the proteomic cargo of AT-MSC-sEVs shifts in response to proinflammatory cytokines. TSG-6 and A20, key molecules implicated in the immunopotency of MSCs, are both part of the molecular content of cytokine-primed ATMSC-sEVs.

TSG-6 is a multi-functional protein involved in several anti-inflammatory processes, including the inhibition of neutrophil transendothelial migration and chemotaxis; the shift of macrophages to an anti-inflammatory M2 phenotype; and the inhibition of $\mathrm{T}$ cell activation and IFN- $\gamma$ secretion $[48,66,67]$. TSG- 6 secretion has been shown to be necessary for MSC's immunomodulatory effects in several models of inflammation (e.g., cornea injury, peritonitis, myocardial infarction, and lung injury). Umbilical cord-derived MSC (UC-MSC) EVs contain TSG-6, which is responsible for their therapeutic effects in experimental bronchopulmonary dysplasia [68]. This emphasizes the importance of TSG-6 in mediating the anti-inflammatory effects of MSC-EVs. Our study shows that primed (but not resting) AT-MSCs may use EV biogenesis pathway to release TSG-6 to the microenvironment.

A20 is a cytoplasmic protein that terminates nuclear factor- $k B$ (NF- $k B$ ) signaling [69]. Mutations in A20/ TNFAIP3 locus have been associated with inflammatory diseases/conditions such as rheumatoid arthritis, systemic lupus erythematosus, and coronary artery disease [70-72]. In the absence of A20, transgenic mice display LPS/TNF hypersensitivity and are unable to limit inflammation, resulting in premature death [73]. The importance of A20 to the immunosuppressive properties of MSCs has only been demonstrated once in a mouse melanoma model [47]. More evidence is needed to understand the mechanism by which MSC-derived A20 acts on recipient immune cells. To date, A20 has only been identified in EVs secreted by TNF- $\alpha$-treated endothelial cells; the functional importance of which is not yet known [74]. Herein, we provide evidence that AT-MSCs secrete A20 into the extracellular space via small exosome-like EVs in response to IFN- $\gamma$ and TNF- $\alpha$. Given the importance of TSG-6 and A20 in immunomodulation, these proteins could serve as useful biomarkers for the selection of anti-inflammatory MSC-sEVs for clinical applications.

Many published studies that previously evaluated the in vitro anti-inflammatory effects of MSC-EVs yielded inconsistent results due to differences in MSC sources, modes of EV collection, and in vitro potency assay designs [75-78]. We show that cytokine-primed AT-MSCs produce sEVs that can inhibit the proliferation of ConAstimulated $\mathrm{CD}^{+} \mathrm{T}$ cells at concentrations of 10 and $20 \mu \mathrm{g} / \mathrm{ml}$. Taking into account that the sEV protein yield per million MSCs was $15 \pm 7.4 \mu \mathrm{g}(n=7)$, the suppressive capacity of MSC-sEVs is significantly less than that exerted by the parental cells or MSC CM. However, this does not exclude the possibility that sEVs work synergistically with other soluble factors to achieve greater $\mathrm{T}$ cell inhibition.

Rab27b is responsible for cytokine-primed MSC-EV release, and its inhibition with siRNA reduces the release of these sEVs and inhibits the secretion of the antiinflammatory molecule TSG- 6 . The siRab27b treatment did not completely abrogate $R A B 27 B$ expression in ATMSCs; therefore, we can only speculate that a complete knockdown of Rab27b may result in full inhibition of the release of TSG-6 containing sEVs. Given that Rab27b mediated TSG-6 secretion may be essential to MSC immunopotency, future studies should test whether $R A B 27 B$ measurement may predict MSC-EV production and their capacity to reduce inflammation [48]. Recent reports implicate Rab27-dependent sEV production in regulating immunity [79]. In the absence of RAB27A/B, mice develop chronic low-grade inflammation and are not able to mount an immune response to inflammatory stimuli, i.e., lipopolysaccharide (LPS) [79]. Further studies are needed to confirm whether MSC-EV release and TSG-6/A20 secretion is abrogated in RAB27 double knock-out mice and whether defects in this inflammation-resolving mechanism contribute to accelerated aging ("inflamm-aging") [80, 81].

In this paper, we show differences in $R A B 27 B$ expression and small exosome-like EV secretion between MSC pediatric and adult donors. Age was associated with lower RAB27B expression and sEV secretion by MSCs. This points to a new role of RAB27B and is consistent with previous data indicating that developmental maturity (embryonic stem cell [ESC]- vs UC-MSC) is inversely correlated with sEV yield [82]. We report that RAB27B mediates the release of anti-inflammatory sEVs by primed MSCs and that lower RAB27B expression is associated with age. $R A B 27 B$ screening may therefore be tested as a predictor of clinical outcomes post-MSC treatment of inflammatory conditions. 


\section{Conclusions}

Subcellular MSC products are evaluated as therapeutics on the basis of their potential superior safety profile and functional stability upon storage compared to MSCs. The results we present indicate that the quantity of MSC-derived EVs and their cargo vary according to the MSC activation state and the MSC donor's age. Ultimately, these results support the notion that "not all MSCEVs are created equal." This concept is clinically relevant and stresses the importance of optimizing EV preparations, including cytokine priming as a way to enhance MSC-EV yields and therapeutic efficacy. In addition, our results highlight the existence of age-associated differences in MSC vesiculation and suggest that reduced immunoregulatory effects of MSCs from older donors may be linked to age-related changes in cellular EV profiles.

\section{Supplementary Information}

The online version contains supplementary material available at https://doi. org/10.1186/s13287-020-02050-6.

\section{Additional file 1.}

\section{Abbreviations}

A20: Tumor necrosis factor alpha-induced protein 3 (TNFAIP3); ALIX: ALG-2interacting protein X; ANX: Annexin; AT: Adipose tissue; AT-MSC: Adipose tissue derived multipotent mesenchymal stromal cells; bFGF: Basic fibroblast growth factor; BM: Bone marrow; BM-MSC: Bone marrow-derived multipotent mesenchymal stromal cells; CHMP4B: Charged multivesicular body protein 4B; CM: Conditioned media; ConA: Concanavalin A; EGF: Epidermal growth factor; EVs: Extracellular vesicles; ESCRT: Endosomal sorting complex required for export; FBS: Fetal bovine serum; FLOT1: Flotilin 1; HGF: Hepatocyte growth factor; HSP: Heat shock protein; ICAM1: Intercellular adhesion molecule 1 (CD54); IFN- $\gamma$ : Interferon gamma; IGF-1: Insulin-like growth factor 1; IL: Interleukin; LAMP: Lysosomal-associated membrane proteins; MFGE8: Milk fat globule_epidermal growth factor_factor VIII (lactadherin); MSC: Multipotent mesenchymal stromal cells; MSC CM: Multipotent mesenchymal stromal cell-conditioned media; MSC-EVs: Multipotent mesenchymal stromal cell-derived extracellular vesicles; NF-kB: Nuclear factor kappa B; PDC6IP: Programmed cell death 6-interacting protein; $\mathrm{PGE}_{2}$ : Prostaglandin E2; RAB27B: Member RAS oncogene family; RIMUHC: Research Institute of the McGill University Health Centre; SDCBP: Syndecan binding protein; sEVs: Small extracellular vesicles; siRNA: Small interfering RNA; TEM: Transmission electron microscopy; TFRC: Transferrin receptor; TGF- $\beta 1$ : Transforming growth factor beta 1; TNFa: Tumor necrosis factor alpha; TSG-6: Tumor necrosis factor alpha-inducible Protein 6 (TNFAIP6); VEGF: Vascular endothelial growth factor

\section{Acknowledgements}

We thank Laura Montermini and Dr. Esterina D'Asti for their technical assistance and expertise with EV characterization and vesiculome experiments. We are thankful for the help of Dr. Martin Olivier and his laboratory members with transmission electron microscopy. This study was supported by an Operating grant from the Canadian Institutes of Health Research (MOP125857).

\section{Authors' contributions}

AC contributed to the conception and design, collection of data, data analysis and interpretation, and manuscript writing. DC contributed to the collection of data, data analysis, and interpretation. ML contributed to the conception and design, data analysis, and interpretation. DS-T contributed to the provision of study material. JR contributed to the conception and design, data analysis and interpretation, manuscript revision, and input of critical intellectual content. IC contributed to the financial support, conception and design, data analysis and interpretation, and final approval of manuscript. The author(s) read and approved the final manuscript.

\section{Funding}

This study was funded by a grant from the Canadian Institutes of Health Research (CIHR\# MOP125857).

\section{Availability of data and materials}

The datasets used and/or analyzed during the current study are available from the corresponding author on reasonable request.

Ethics approval and consent to participate

This study was approved by the McGill University Health Center Ethics Review Board (\#10-107).

\section{Consent for publication}

Not applicable.

\section{Competing interests}

The authors declare that they have no competing interests.

\section{Author details}

${ }^{1}$ Research Institute of the McGill University Health Centre, McGill University, 1001 Decarie Blvd, Office \# EM2-3238, Montreal, QC H4A 3J1, Canada. 2Division of Cardiac Surgery, Department of Surgery, McGill University, Montreal, QC, Canada. ${ }^{3}$ Division of Rheumatology, Department of Medicine, McGill University, Montreal, QC, Canada.

Received: 26 August 2020 Accepted: 25 November 2020

Published online: 14 December 2020

\section{References}

1. Spees $\mathrm{L}$, Lee RH, Gregory CA. Mechanisms of mesenchymal stem/stromal cell function. Stem Cell Res Ther. 2016;7(1):125.

2. Mattar P, Bieback K. Comparing the immunomodulatory properties of bone marrow, adipose tissue, and birth-associated tissue mesenchymal stromal cells. Front Immunol. 2015;6:560.

3. Galipeau J, Sensébé L. Mesenchymal stromal cells: clinical challenges and therapeutic opportunities. Cell Stem Cell. 2018;22(6):824-33.

4. Noronha NC, Mizukami A, Caliari-Oliveira C, Cominal JG, Rocha JLM, Covas DT, et al. Priming approaches to improve the efficacy of mesenchymal stromal cell-based therapies. Stem Cell Res Ther. 2019;10(1):131.

5. Von Bahr L, Batsis I, Moll G, Hägg M, Szakos A, Sundberg B, et al. Analysis of tissues following mesenchymal stromal cell therapy in humans indicates limited long-term engraftment and no ectopic tissue formation. Stem Cells. 2012;30(7):1575-8

6. Iso Y, Spees JL, Serrano C, Bakondi B, Pochampally R, Song Y-H, et al. Multipotent human stromal cells improve cardiac function after myocardial infarction in mice without long-term engraftment. Biochem Biophys Res Commun. 2007;354(3):700-6.

7. Lee RH, Pulin AA, Seo MJ, Kota DJ, Ylostalo J, Larson BL, et al. Intravenous hMSCs improve myocardial infarction in mice because cells embolized in lung are activated to secrete the anti-inflammatory protein TSG-6. Cell Stem Cell. 2009;5(1):54-63.

8. Gnecchi M, Danieli P, Malpasso G, Ciuffreda MC. Paracrine mechanisms of mesenchymal stem cells in tissue repair. Mesenchymal Stem Cells: Springer; 2016. p. 123-46

9. Timmers L, Lim SK, Hoefer IE, Arslan F, Lai RC, van Oorschot AA, et al, Human mesenchymal stem cell-conditioned medium improves cardiac function following myocardial infarction. Stem Cell Res. 2011;6(3):206-14.

10. Gnecchi M, He H, Noiseux N, Liang OD, Zhang L, Morello F, et al. Evidence supporting paracrine hypothesis for Akt-modified mesenchymal stem cellmediated cardiac protection and functional improvement. FASEB J. 2006; 20(6):661-9

11. Timmers L, Lim SK, Arslan F, Armstrong JS, Hoefer IE, Doevendans PA, et al. Reduction of myocardial infarct size by human mesenchymal stem cell conditioned medium. Stem Cell Res. 2008;1(2):129-37.

12. Pawitan JA. Prospect of stem cell conditioned medium in regenerative medicine. Biomed Res Int. 2014;2014(965849):14. https://doi.org/10.1155/ 2014/965849. 
13. Konala VBR, Mamidi MK, Bhonde R, Das AK, Pochampally R, Pal R. The current landscape of the mesenchymal stromal cell secretome: a new paradigm for cell-free regeneration. Cytotherapy. 2016;18(1):13-24.

14. Ferreira JR, Teixeira GQ, Santos SG, Barbosa MA, Almeida-Porada G, Gonçalves RM. Mesenchymal stromal cell secretome: influencing therapeutic potential by cellular pre-conditioning. Front Immunol. 2018;9: 2837.

15. Najar M, Krayem M, Merimi M, Burny A, Meuleman N, Bron D, et al. Insights into inflammatory priming of mesenchymal stromal cells: functional biological impacts. Inflamm Res. 2018;67(6):467-77.

16. Ryan J, Barry F, Murphy J, Mahon BP. Interferon- $\gamma$ does not break, but promotes the immunosuppressive capacity of adult human mesenchymal stem cells. Clinical Experimental Immunol. 2007;149(2):353-63.

17. Aggarwal S, Pittenger MF. Human mesenchymal stem cells modulate allogeneic immune cell responses. Blood. 2005;105(4):1815-22.

18. Linero I, Chaparro O. Paracrine effect of mesenchymal stem cells derived from human adipose tissue in bone regeneration. PLoS One. 2014;9(9): e107001.

19. Deatherage BL, Cookson BT. Membrane vesicle release in bacteria, eukaryotes, and archaea: a conserved yet underappreciated aspect of microbial life. Infect Immun. 2012;80(6):1948-57.

20. Thery C, Witwer KW, Aikawa E, Alcaraz MJ, Anderson JD, Andriantsitohaina $R$, et al. Minimal information for studies of extracellular vesicles 2018 (MISE V2018): a position statement of the International Society for Extracellular Vesicles and update of the MISEV2014 guidelines. J Extracell Vesicles. 2018; 7(1):1535750.

21. van Niel G, D'Angelo G, Raposo G. Shedding light on the cell biology of extracellular vesicles. Nat Rev Mol Cell Biol. 2018;19(4):213-28.

22. Allan D, Tieu A, Lalu M, Burger D. Mesenchymal stromal cell-derived extracellular vesicles for regenerative therapy and immune modulation: Progress and challenges toward clinical application. Stem Cell Transl Med. 2020;9(1):39-46.

23. Lee $\mathrm{TH}$, Chennakrishnaiah S, Audemard E, Montermini L, Meehan B, Rak J. Oncogenic ras-driven cancer cell vesiculation leads to emission of doublestranded DNA capable of interacting with target cells. Biochem Biophys Res Commun. 2014;451(2):295-301.

24. Valadi H, Ekström K, Bossios A, Sjöstrand M, Lee JJ, Lötvall JO. Exosomemediated transfer of mRNAs and microRNAs is a novel mechanism of genetic exchange between cells. Nat Cell Biol. 2007;9(6):654-9.

25. Skog J, Würdinger T, Van Rijn S, Meijer DH, Gainche L, Curry WT Jr, et al. Glioblastoma microvesicles transport RNA and proteins that promote tumour growth and provide diagnostic biomarkers. Nat Cell Biol. 2008; 10(12):1470-6.

26. Lai RC, Arslan F, Lee MM, Sze NSK, Choo A, Chen TS, et al. Exosome secreted by MSC reduces myocardial ischemia/reperfusion injury. Stem Cell Res. 2010;4(3):214-22.

27. Zhang $H$, Xiang M, Meng D, Sun N, Chen S. Inhibition of myocardial ischemia/reperfusion injury by exosomes secreted from mesenchymal stem cells. Stem Cells Int. 2016;2016:4328362. Published online 2016 Apr 26. https://doi.org/10.1155/2016/4328362.

28. Akyurekli C, Le Y, Richardson RB, Fergusson D, Tay J, Allan DS. A systematic review of preclinical studies on the therapeutic potential of mesenchymal stromal cell-derived microvesicles. Stem Cell Rev Rep. 2015;11(1):150-60.

29. Kizilay Mancini Ö, Lora M, Shum-Tim D, Nadeau S, Rodier F, Colmegna I. A proinflammatory secretome mediates the impaired immunopotency of human mesenchymal stromal cells in elderly patients with atherosclerosis. Stem Cells Transl Med. 2017:6(4):1132-40.

30. Mancini OK, Shum-Tim D, Stochaj U, Correa JA, Colmegna I. Age, atherosclerosis and type 2 diabetes reduce human mesenchymal stromal cell-mediated T-cell suppression. Stem Cell Res Ther. 2015;6(1):140.

31. Eitan E, Green J, Bodogai M, Mode NA, Bæk R, Jørgensen MM, et al. Agerelated changes in plasma extracellular vesicle characteristics and internalization by leukocytes. Sci Rep. 2017;7(1):1342.

32. Freeman DW, Hooten NN, Eitan E, Green J, Mode NA, Bodogai M, et al. Altered extracellular vesicle concentration, cargo, and function in diabetes. Diabetes. 2018;67(11):2377-88.

33. Zhang $X$, Hubal MJ, Kraus VB. Immune cell extracellular vesicles and their mitochondrial content decline with ageing. Immun Ageing. 2020;17:1.

34. Dominici M, Le Blanc K, Mueller I, Slaper-Cortenbach I, Marini F, Krause D, et al. Minimal criteria for defining multipotent mesenchymal stromal cells.
The International Society for Cellular Therapy position statement. Cytotherapy. 2006;8(4):315-7.

35. Krampera M, Galipeau J, Shi Y, Tarte K, Sensebe L. Immunological characterization of multipotent mesenchymal stromal cells-the International Society for Cellular Therapy (ISCT) working proposal. Cytotherapy. 2013;15(9):1054-61.

36. Lötvall J, Hill AF, Hochberg F, Buzás El, Di Vizio D, Gardiner C, et al. Minimal experimental requirements for definition of extracellular vesicles and their functions: a position statement from the International Society for Extracellular Vesicles: Taylor Francis; 2014.

37. Théry C, Amigorena S, Raposo G, Clayton A. Isolation and characterization of exosomes from cell culture supernatants and biological fluids. Current Protocols Cell Biol. 2006;30(1):3.22. 1-3. 9.

38. Dragovic RA, Gardiner C, Brooks AS, Tannetta DS, Ferguson DJ, Hole P, et al. Sizing and phenotyping of cellular vesicles using nanoparticle tracking analysis. Nanomedicine. 2011;7(6):780-8.

39. Spinelli C, Montermini L, Meehan B, Brisson A, Tan S, Choi D, et al. Molecular subtypes and differentiation programmes of glioma stem cells as determinants of extracellular vesicle profiles and endothelial cell-stimulating activities. J Extracellular Vesicles. 2018;7(1):1490144.

40. Schmittgen TD, Livak KJ. Analyzing real-time PCR data by the comparative C T method. Nat Protoc. 2008;3(6):1101.

41. Lobb RJ, Becker M, Wen SW, Wong CS, Wiegmans AP, Leimgruber A, et al. Optimized exosome isolation protocol for cell culture supernatant and human plasma. J Extracell Vesicles. 2015;4:27031.

42. Atayde VD, Aslan H, Townsend S, Hassani K, Kamhawi S, Olivier M. Exosome secretion by the parasitic protozoan Leishmania within the sand fly midgut. Cell Rep. 2015;13(5):957-67.

43. Bobrie A, Colombo M, Raposo G, Thery C. Exosome secretion: molecular mechanisms and roles in immune responses. Traffic. 2011;12(12):1659-68.

44. Théry C, Witwer KW, Aikawa E, Alcaraz MJ, Anderson JD, Andriantsitohaina R, et al. Minimal information for studies of extracellular vesicles 2018 (MISE V2018): a position statement of the International Society for Extracellular Vesicles and update of the MISEV2014 guidelines. J Extracellular Vesicles. 2018;7(1):1535750

45. Kowal J, Arras G, Colombo M, Jouve M, Morath JP, Primdal-Bengtson B, Dingli F, Loew D, Tkach M, Théry C. Proteomic comparison defines novel markers to characterize heterogeneous populations of extracellular vesicle subtypes. Proc Natl Acad Sci U S A. 2016;113(8):E968-77. https://doi.org/10. 1073/pnas.1521230113. Epub 2016 Feb 8.

46. Di Trapani M, Bassi G, Midolo M, Gatti A, Kamga PT, Cassaro A, et al. Differential and transferable modulatory effects of mesenchymal stromal cell-derived extracellular vesicles on T, B and NK cell functions. Scientific Reports. 2016;6:24120.

47. Dang RJ, Yang YM, Zhang L, Cui DC, Hong B, Li P, et al. A20 plays a critical role in the immunoregulatory function of mesenchymal stem cells. J Cell Mol Med. 2016;20(8):1550-60.

48. Kota DJ, Wiggins LL, Yoon N, Lee RH. TSG-6 produced by hMSCs delays the onset of autoimmune diabetes by suppressing Th1 development and enhancing tolerogenicity. Diabetes. 2013;62(6):2048-58.

49. C-y L, Wu X-y, J-b T, Yang X-X, J-I Z, Zheng Q-f, et al. Comparative analysis of human mesenchymal stem cells from bone marrow and adipose tissue under xeno-free conditions for cell therapy. Stem Cell Res Ther. 2015;6(1):55.

50. Melief SM, Zwaginga JJ, Fibbe WE, Roelofs H. Adipose tissue-derived multipotent stromal cells have a higher immunomodulatory capacity than their bone marrow-derived counterparts. Stem Cells Transl Med. 2013;2(6):455-63.

51. Kanemoto S, Nitani R, Murakami T, Kaneko M, Asada R, Matsuhisa K, et al. Multivesicular body formation enhancement and exosome release during endoplasmic reticulum stress. Biochem Biophys Res Commun. 2016;480(2): 166-72.

52. Desdín-Micó G, Mittelbrunn M. Role of exosomes in the protection of cellular homeostasis. Cell Adhes Migr. 2017;11(2):127-34.

53. Garcia NA, Ontoria-Oviedo I, González-King H, Diez-Juan A, Sepúlveda P. Glucose starvation in cardiomyocytes enhances exosome secretion and promotes angiogenesis in endothelial cells. PLoS One. 2015;10(9):e0138849.

54. Tan CY, Lai RC, Wong W, Dan YY, Lim S-K, Ho HK. Mesenchymal stem cellderived exosomes promote hepatic regeneration in drug-induced liver injury models. Stem Cell Res Ther. 2014;5(3):76.

55. Blazquez R, Sanchez-Margallo FM, de la Rosa O, Dalemans W, Álvarez V, Tarazona $R$, et al. Immunomodulatory potential of human adipose 
mesenchymal stem cells derived exosomes on in vitro stimulated T cells. Front Immunol. 2014;5:556

56. Shelke GV, Lässer C, Gho YS, Lötvall J. Importance of exosome depletion protocols to eliminate functional and RNA-containing extracellular vesicles from fetal bovine serum. J Extracellular Vesicles. 2014;3(1):24783.

57. Ostrowski M, Carmo NB, Krumeich S, Fanget I, Raposo G, Savina A, et al Rab27a and Rab27b control different steps of the exosome secretion pathway. Nat Cell Biol. 2010;12(1):19.

58. Chairoungdua A, Smith DL, Pochard P, Hull M, Caplan MJ. Exosome release of $\beta$-catenin: a novel mechanism that antagonizes Wnt signaling. J Cell Biol. 2010;190(6):1079-91.

59. Song Y, Dou H, Li X, Zhao X, Li Y, Liu D, et al. Exosomal miR-146a contributes to the enhanced therapeutic efficacy of interleukin-1 $\beta$-primed mesenchymal stem cells against sepsis. Stem Cells. 2017;35(5):1208-21.

60. Ti D, Hao H, Tong C, Liu J, Dong L, Zheng J, et al. LPS-preconditioned mesenchymal stromal cells modify macrophage polarization for resolution of chronic inflammation via exosome-shuttled let-7b. J Transl Med. 2015;13(1):308.

61. Toh WS, Lai RC, Zhang B, Lim SK. MSC exosome works through a proteinbased mechanism of action. Biochem Soc Trans. 2018;46(4):843-53.

62. Anderson JD, Johansson HJ, Graham CS, Vesterlund M, Pham MT, Bramlett $\mathrm{CS}$, et al. Comprehensive proteomic analysis of mesenchymal stem cell exosomes reveals modulation of angiogenesis via nuclear factor-KappaB signaling. Stem Cells. 2016;34(3):601-13.

63. Tovar I, Guerrero R, Lopez-Penalver JJ, Exposito J, Ruiz de Almodovar JM. Rationale for the use of radiation-activated mesenchymal stromal/stem cells in acute respiratory distress syndrome. Cells. 2020;9(9):2015. https://doi.org/ 10.3390/cells9092015.

64. Collino F, Lopes JA, Correa S, Abdelhay E, Takiya CM, Wendt CHC, et al. Adipose-derived mesenchymal stromal cells under hypoxia: changes in extracellular vesicles secretion and improvement of renal recovery after ischemic injury. Cell Physiol Biochem. 2019;52(6):1463-83.

65. Yuan O, Lin C, Wagner J, Archard JA, Deng P, Halmai J, et al. Exosomes derived from human primed mesenchymal stem cells induce mitosis and potentiate growth factor secretion. Stem Cells Dev. 2019;28(6):398-409.

66. Dyer DP, Thomson JM, Hermant A, Jowitt TA, Handel TM, Proudfoot AE, et al. TSG-6 inhibits neutrophil migration via direct interaction with the chemokine CXCL8. J Immunol. 2014;192(5):2177-85.

67. Mittal M, Tiruppathi C, Nepal S, Zhao Y-Y, Grzych D, Soni D, et al. TNFastimulated gene-6 (TSG6) activates macrophage phenotype transition to prevent inflammatory lung injury. Proc Natl Acad Sci. 2016;113(50):E8151-E8.

68. Chaubey S, Thueson S, Ponnalagu D, Alam MA, Gheorghe CP, Aghai Z, et al. Early gestational mesenchymal stem cell secretome attenuates experimental bronchopulmonary dysplasia in part via exosome-associated factor TSG-6. Stem Cell Res Ther. 2018;9(1):173.

69. Catrysse L, Vereecke L, Beyaert R, van Loo G. A20 in inflammation and autoimmunity. Trends Immunol. 2014;35(1):22-31.

70. Shimane K, Kochi Y, Horita T, Ikari K, Amano H, Hirakata M, et al. The association of a nonsynonymous single-nucleotide polymorphism in TNFA IP3 with systemic lupus erythematosus and rheumatoid arthritis in the Japanese population. Arthritis Rheumatism. 2010;62(2):574-9.

71. Graham RR, Cotsapas C, Davies L, Hackett R, Lessard CJ, Leon JM, et al. Genetic variants near TNFAIP3 on $6 \mathrm{q} 23$ are associated with systemic lupus erythematosus. Nat Genet. 2008;40(9):1059.

72. Boonyasrisawat W, Eberle D, Bacci S, Zhang Y-Y, Nolan D, Gervino EV, et al Tag polymorphisms at the A20 (TNFAIP3) locus are associated with lower gene expression and increased risk of coronary artery disease in type 2 diabetes. Diabetes. 2007:56(2):499-505.

73. Lee EG, Boone DL, Chai S, Libby SL, Chien M, Lodolce JP, et al. Failure to regulate TNF-induced NF-KB and cell death responses in A20-deficient mice. Science. 2000;289(5488):2350-4.

74. de Jong OG, Verhaar MC, Chen Y, Vader P, Gremmels H, Posthuma G, et al. Cellular stress conditions are reflected in the protein and RNA content of endothelial cell-derived exosomes. J Extracellular Vesicles. 2012;1 (1):18396.

75. Mokarizadeh A, Delirezh N, Morshedi A, Mosayebi G, Farshid A-A, Mardani K. Microvesicles Derived from Mesenchymal Stem Cells: Potent Organelles for Induction of Tolerogenic Signaling. Immunol Lett. 2012;147(1-2):47-54. https://doi.org/10.1016/j.imlet.2012.06.001. Epub 2012 Jun 15.

76. Teng X, Chen L, Chen W, Yang J, Yang Z, Shen Z. Mesenchymal stem cellderived exosomes improve the microenvironment of infarcted myocardium contributing to angiogenesis and anti-inflammation. Cell Physiol Biochem. 2015;37(6):2415-24.
77. Conforti A, Scarsella M, Starc N, Giorda E, Biagini S, Proia A, et al. Microvescicles derived from mesenchymal stromal cells are not as effective as their cellular counterpart in the ability to modulate immune responses in vitro. Stem Cells Dev. 2014:23(21):2591-9.

78. Gouveia de Andrade AV, Bertolino G, Riewaldt J, Bieback K, Karbanová J, Odendahl $\mathrm{M}$, et al. Extracellular vesicles secreted by bone marrow-and adipose tissue-derived mesenchymal stromal cells fail to suppress lymphocyte proliferation. Stem Cells Dev. 2015;24(11):1374-6.

79. Alexander M, Ramstead AG, Bauer KM, Lee S-H, Runtsch MC, Wallace J, et al. Rab27-dependent exosome production inhibits chronic inflammation and enables acute responses to inflammatory stimuli. J Immunol. 2017;199(10): 3559-70.

80. Fafián-Labora J, Lesende-Rodríguez I, Fernández-Pernas P, Sangiao-Alvarellos $S$, Monserrat L, Arntz O, et al. Effect of age on pro-inflammatory miRNAs contained in mesenchymal stem cell-derived extracellular vesicles. Sci Rep. 2017;7:43923

81. Franceschi $\mathrm{C}$, Bonafè $\mathrm{M}$, Valensin $\mathrm{S}$, Olivieri $\mathrm{F}$, De Luca $\mathrm{M}$, Ottaviani $\mathrm{E}$, et al. Inflamm-aging: an evolutionary perspective on immunosenescence. Ann N Y Acad Sci. 2000;908(1):244-54.

82. Yeh Yeo RW. Efficiency of exosome production correlates inversely with the developmental maturity of MSC donor; 2013.

\section{Publisher's Note}

Springer Nature remains neutral with regard to jurisdictional claims in published maps and institutional affiliations.
Ready to submit your research? Choose BMC and benefit from:

- fast, convenient online submission

- thorough peer review by experienced researchers in your field

- rapid publication on acceptance

- support for research data, including large and complex data types

- gold Open Access which fosters wider collaboration and increased citations

- maximum visibility for your research: over $100 \mathrm{M}$ website views per year

At $\mathrm{BMC}$, research is always in progress.

Learn more biomedcentral.com/submissions 